\title{
Astrobiology field research in Moon/Mars analogue environments
}

\author{
B.H. Foing ${ }^{1,2,3}$, C. Stoker ${ }^{4}$ and P. Ehrenfreund ${ }^{5,6}$ \\ ${ }^{1}$ ESA ESTEC, Postbus 299, 2200 AG Noordwijk, The Netherlands \\ ${ }^{2}$ Faculty of Earth and Life Sciences, VU University Amsterdam, 1081 HV Amsterdam, The Netherlands \\ ${ }^{3}$ International Lunar Exploration Working Group (ILEWG), clo BH Foing, ESTEC PO Box 299, 2200 AG Noordwijk, \\ The Netherlands \\ ${ }^{4}$ Space Science Division, M.S. 245-3, NASA Ames Research Center, CA 94035, USA \\ ${ }^{5}$ Leiden Institute of Chemistry, P O Box 9502, 2300 Leiden, The Netherlands \\ ${ }^{6}$ Space Policy Institute, Elliott School of International Affairs, Washington, DC, USA \\ e-mail: Bernard.Foing@esa.int
}

\begin{abstract}
Extreme environments on Earth often provide similar terrain conditions to landing/operation sites on Moon and Mars. Several field campaigns (EuroGeoMars2009 and DOMMEX/ILEWG EuroMoonMars from November 2009 to March 2010) were conducted at the Mars Desert Research Station (MDRS) in Utah. Some of the key astrobiology results are presented in this special issue on 'Astrobiology field research in Moon/Mars analogue environments' relevant to investigate the link between geology, minerals, organics and biota. Preliminary results from a multidisciplinary field campaign at Rio Tinto in Spain are presented.
\end{abstract}

Received 29 March 2011, accepted 6 April 2011, first published online 28 April 2011

Key words: Mars, Moon, astrobiology, desert field research sites, minerals, organics, biota, extreme environments, space instrumentation, planetary exploration.

\section{Introduction}

Robotic and human operations on planetary surfaces can be well-practiced in terrestrial analogue environments. Field expeditions at such planetary analogue sites and supporting laboratory research enhance our scientific knowledge for planetary exploration and allow us to test technologies, methodologies and protocols, and train instrument and operations teams.

In this special issue of the International Journal of Astrobiology, we report on the astrobiology results obtained from field analogue campaigns at the Mars Desert Research Station (MDRS) in Utah. The research was supported by NASA Ames Research Center, the International Lunar Exploration Working Group (ILEWG), ESA/ESTEC and several academic partners and by facilities provided by the Mars Society.

\section{Summary of results and articles}

In paper 1, 'Field astrobiology research in Moon-Mars analogue environment: instruments and methods', Foing et al. (2011b) describe the experimental approach, validation of instruments and in-situ measurements during the EuroGeoMars2009 campaign. The paper describes sample handling as well as the analysis of rocks and soils using microscopy, spectrometry, X-ray diffraction and fluorescence $\mathrm{XRD/XRF}$. Specific results on endolithic microbial mats are reported.

In paper 2, 'Concretions in exhumed and inverted channels near Hanksville Utah: implications for Mars’, Clarke \& Stoker
(2011) discuss a diversity of Mars analogue features in the landscape near MDRS. These include exhumed and inverted paleochannels. Concretions of $0.5-1 \mathrm{~cm}$ size were investigated with morphology and surface expression similar to haematite 'blueberries' found at Meridiani planum on Mars, but with different composition.

In paper 3, 'PCR-based analysis of microbial communities during the EuroGeoMars campaign at Mars Desert Research Station, Utah', Thiel et al. (2011a) demonstrate the technical feasibility of a Polymerase Chain Reaction (PCR) based analysis of microbial communities in soil and water samples performed on-site in the MDRS habitat laboratory. They successfully investigated the microbial diversity in collected samples by PCR-mediated detection of ribosomal DNA from bacteria, archaea and eukarya.

In paper 4, 'A wide variety of putative extremophiles and large beta-diversity at the Mars Desert Research Station (Utah)', Direito et al. (2011) performed culture-independent molecular analysis directed at ribosomal RNA for the three domains of life on returned samples from the EuroGeoMars campaign. Spiking experiments revealed that the absence of life in some samples is due to adsorption or degradation of DNA on the mineral surface. The phyllogenetic analysis revealed a variety of putative extremophiles.

In paper 5, 'Analysis of Mars analogue soil samples using solid-phase microextraction, organic solvent extraction and gas chromatography/mass spectrometry', Orzechowska et al. (2011) used solid-phase microextraction (SPME) for screening and characterization of two- and three-ring polycyclic aromatic hydrocarbons (PAHs) in soil samples. Complementary liquid extraction was used to measure five- and six-ring 
PAH compounds. The measured samples showed very low PAH concentrations from 1 to $60 \mathrm{ng} / \mathrm{g}$.

In paper 6, 'Analysis of mineral matrices of planetary soils analogs from the Utah Desert', Kotler et al. (2011) measure the mineralogy of returned soil samples using X-ray diffraction and Fourier-transform Infrared spectroscopy. Hydrated sulfates, phyllosilicates and carbonates with different composition (bearing $\mathrm{Ca}, \mathrm{Mg}, \mathrm{Fe}$ and $\mathrm{Mn}$ ) were identified. Special emphasis is given to the composition of smectites.

In paper 7, 'Extraction of amino acids from soils close to the Mars Desert Research Station (MDRS), Utah', Martins et al. (2011) find a large difference of amino acid abundances among the collected soil samples, with values ranging from 0 to 100000 parts per billion (ppb). These data, interpreted in the context of clay matrix content, have implications for future organics and life detection missions.

In paper 8, 'Astrobiology and habitability studies in preparation for future Mars missions: trends from investigating minerals, organics and biota', Ehrenfreund et al. (2011) compare the measurements of mineralogy, organics and biota of ten selected sample sites from the vicinity of MDRS collected during the EuroGeoMars2009 campaign. The results are interpreted in the context of future missions that target the identification of organic molecules and biomarkers on Mars.

In paper 9, 'Human crew related aspects for astrobiology research', Thiel et al. (2011b) describe the boundary conditions for astrobiology research, the habitat and laboratory layout, the biology instruments and technical aspects. Social and operational aspects for conducting astrobiology and other investigations are discussed.

In paper 10, 'Mineralogical, chemical, organic and microbial properties of subsurface soil cores from Mars Desert Research Station (Utah, USA): phyllosilicate and sulfate analogues to Mars mission landing sites', Stoker et al. (2011) describe the analysis of subsurface soil cores collected in November 2009 and March 2010 (DOMMEXEuroMoonMars campaigns). The soil cores were collected from four geological formations and mineralogy was measured with Terra, a field version of the CheMin XRD to be used on Mars Science Laboratory MSL (to land in 2012). The results indicate the presence of phyllosilicates, evaporates and sulfates, analogues to what is expected for the MSL landing site. The depositional environment, geological history and how the mineralogy affects the ability to preserve and detect organics are discussed.

In paper 11, 'Multidisciplinary integrated field campaign to an acidic Martian Earth analogue with astrobiological interest: Rio Tinto', Gómez et al. (2011) study the mineral context and the chemolithotrophic activity of micro-organisms thriving on local pyrite. Results from a cross-instruments study (CAREX campaign) of Rio Tinto as an extreme acidic Mars analogue environment are discussed.

\section{Perspectives}

The results from EuroGeoMars2009 and DOMMEX-ILEWG EuroMoonMars 2009-2010 field campaigns in the Utah desert confirm that this environment is well suited as planetary analogue site. Research performed in this geological diverse arid desert can address questions relevant to Mars processes and astrobiology and be used to interpret data from current Mars orbiters and rovers, and to support the upcoming Mars landers. Key issues include the optimization of instrument performance, techniques and methods, sample acquisition and extraction, the correlative analysis of minerals, organics, environmental parameters, geological/geochemical history and biosignatures.

\section{Acknowledgements}

We thank NASA Ames, ESTEC, ILEWG, the Vrije Universiteit Amsterdam and partner institutes for experimental, operational and science support. We thank the MDRS mission support and the Mars Society and ESTEC ExoGeoLab remote support. We acknowledge research travel grants from ILEWG and NASA Spaceward bound programme, and the support from EuroGeoMars2009 teams and crew members. We also thank the crews from DOMMEXILEWG EuroMoonMars 2009-2010 campaigns and support from NASA, Ecole de l' Air, ESTEC and VU Amsterdam. We thank the authors and co-authors of the papers from this special issue for their coordinated contribution, all the referees for critical and constructive comments, and the IJA production staff for their efficiency.

\section{References}

Clarke, J.D.A. \& Stoker, C.R. (2011). Concretions in exhumed and inverted channels near Hanksville Utah: implications for Mars. Int. J. Astrobiol. 10, 161-175.

Direito, S.O.L., Ehrenfreund, P., Marees, A., Staats, M., Foing, B.H. \& Röling, W.F.M. (2011). A wide variety of putative extremophiles and large beta-diversity at the Mars Desert Research Station (Utah). Int. J. Astrobiol. 10, 191-207.

Ehrenfreund, P., Röling, W.F.M., Thiel, C.S., Quinn, R., Septhon, M.A., Stoker, C., Direito, S., Kotler, J.M., Martins, Z., Orzechowska, G.E. et al. (2011). Astrobiology and habitability studies in preparation for future Mars missions: trends from investigating minerals, organics and biota. Int. J. Astrobiol. 10, 239-253.

Foing, B.H., Stoker, C. \& Ehrenfreund, P. (eds) (2011a). Astrobiology field research in Moon/Mars analogue environments. Special Issue, Int. J. Astrobiol. 10, 137-139.

Foing, B.H., Stoker, C., Zavaleta, J., Ehrenfreund, P., Thiel, C., Sarrazin, P., Blake, D., Page, J., Pletser, V., Hendrikse, J. et al. (2011b). Field astrobiology research in Moon-Mars analogue environment: instruments and methods. Int. J. Astrobiol. 10, 141-160.

Gómez, F., Walter, N., Amils, R., Rull, F., Klingelhöfer, A.K., Kviderova, J., Sarrazin, P., Foing, B., Behar, A., Fleischer, I. et al. (2011). Multidisciplinary integrated field campaign to an acidic Martian Earth analogue with astrobiological interest: Rio Tinto. Int. J. Astrobiol. 10, 291-305.

Kotler, J.M., Quinn, R.C., Foing, B.H., Martins, Z. \& Ehrenfreund, P. (2011). Analysis of Mineral Matrices of planetary soils analogs from the Utah Desert. Int. J. Astrobiol. 10, 221-229.

Martins, Z., Sephton, M.A., Foing, B.H. \& Ehrenfreund, P. (2011). Extraction of amino acids from soils close to the Mars Desert Research Station (MDRS), Utah. Int. J. Astrobiol. 10, 231-238.

Orzechowska, G.E., Kidd, R.D., Foing, B.H., Kanik, I., Stoker, C. \& Ehrenfreund, P. (2011). Analysis of Mars analogue soil samples using 
solid-phase microextraction, organic solvent extraction and gas chromatography/mass spectrometry. Int. J. Astrobiol. 10, 209-219.

Stoker, C.R., Clarke, J., Direito, S.O.L., Blake, D., Martin, K.R., Zavaleta, J. \& Foing, B. (2011). Mineralogical, chemical, organic and microbial properties of subsurface soil cores from Mars Desert Research Station (Utah, USA): phyllosilicate and sulfate analogues to Mars mission landing sites. Int. J. Astrobiol. 10, 269-289.
Thiel, C.S., Ehrenfreund, P., Foing, B., Pletser, V. \& Ullrich, O. (2011a). PCR-based analysis of microbial communities during the EuroGeoMars campaign at Mars Desert Research Station, Utah. Int. J. Astrobiol. 10, 177-190.

Thiel, C.S., Pletser, V., Foing, B.H. \& the EuroGeoMars Team (2011b). Human crew related aspects for astrobiology research. Int. J. Astrobiol. 10, $255-267$. 